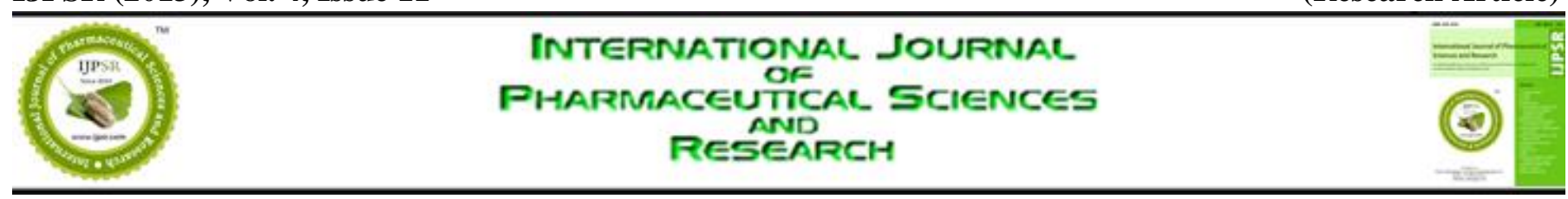

Received on 24 June, 2013; received in revised form, 29 July, 2013; accepted, 25 October, 2013; published 01 November, 2013

\title{
ANALYTICAL METHOD DEVELOPMENT AND VALIDATION OF MARAVIROC IN BULK AND PHARMACEUTICAL FORMULATION BY UV SPECTROSCOPY
}

Sellappan Velmurugan* ${ }^{1,2}$ and Mohamed Ashraf Ali ${ }^{1,3}$

Department of Pharmaceutics, Sunrise University ${ }^{1}$, Alwar, Rajasthan, India

Department of Pharmaceutics, KLR Pharmacy College ${ }^{2}$, Palvoncha, Andhra Pradesh, India

Institute for Research in Molecular Medicine, Universiti Sains Malaysia ${ }^{3}$, Penang, Malaysia

Keywords:

Maraviroc, Ultraviolet spectroscopy, analysis, dosage form, method validation

Correspondence to Author:

Sellappan Velmurugan

Department of Pharmaceutics,

Sunrise University, Alwar,

Rajasthan, India

E-mail: willard_cbe@ @rediffmail.com
ABSTRACT: The aim of present work is to develop and validate simple, sensitive, economical and accurate Spectrophotometric method has been developed for determination of Maraviroc in pure form and in pharmaceutical formulations. Maraviroc in Phosphate buffer $\mathrm{pH}$ 7.4 shows maximum absorbance at $210 \mathrm{~nm}$. Beer's law was obeyed in the concentration range of $5-25 \mu \mathrm{g} / \mathrm{mL}$, The LOD and LOQ were found to be $0.10428 \mu \mathrm{g} / \mathrm{ml}$ and $0.315 \mu \mathrm{g} / \mathrm{ml}$ respectively. A recovery of Maraviroc in tablet formulation was observed in the range of $100.70-103.90 \%$. Percentages assay of Maraviroc in tablet was more than $99.73 \%$. The proposed method is precise simple, accurate, precise, economical and robust and can be used for routine analysis of Maraviroc in bulk and pharmaceutical formulations.
INTRODUCTION: Maraviroc is one of a new class of antiretroviral drug known as CCR5 antagonists and only oral entry inhibitor approved for the treatment of HIV-1infection. These acts as a human immune deficiency virus type 1 (HIV-1) co receptor. Maraviroc binds to the human chemokine receptor CCR5 preventing the interaction of HIV-1 gp 120 and CCR5 necessary for CCR5 tropic HIV 1 to enter cells ${ }^{1,2}$.

Maraviroc has the chemical name 4,4 difluoro $\mathrm{N}\{($ 1S) 3[exo 3(3 isopropyl 5 methyl 4H 1,2,4 triazol 4 yl) 8 azabicyclo [3.2.1] oct 8 yl] 1 phenyl propyl \} cyclohexane carboxamid (fig. 1) ${ }^{3}$. Maraviroc is a white to yellowish or brownish powder with a molecular formula of $\mathrm{C}_{29} \mathrm{H}_{41} \mathrm{~F}_{2} \mathrm{~N}_{5} \mathrm{O}$.

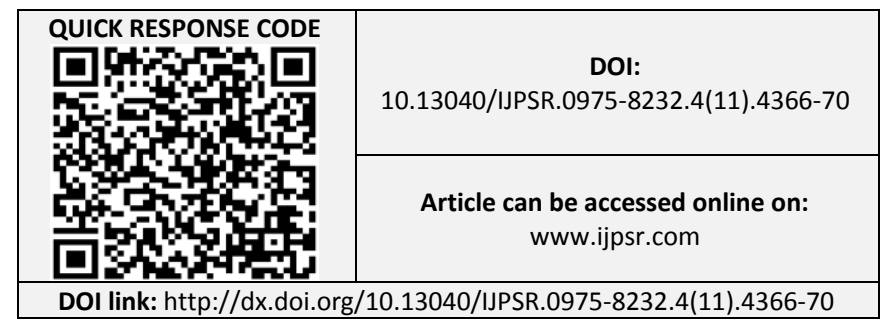

Maraviroc is practically insoluble in water, slightly soluble in ethanol, Soluble in Methanol, Dimethyl sulfoxide and PEG $400^{4}$.

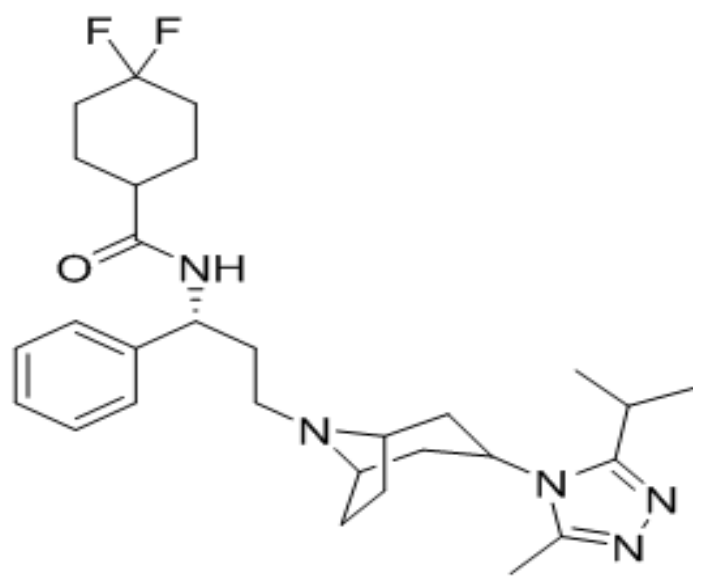

FIG. 1: MARAVIROC CHEMICAL STRUCTURE

Maraviroc belongs to BCS class III drug. Along with its poor water solubility it also have only slight solubility in most of organic solvents, but it have good solubility in Phosphate buffer pH 7.4 ${ }^{5}$. 
MATERIALS AND METHODS: Literature survey reveals that several analytical methods have been reported for the estimation of Maraviroc by HPLC method ${ }^{6,7}$. Apart from above no other work in the literature reported about the UV Spectrophotometric method for the analysis of Maraviroc in pharmaceutical formulations. Thus there is need to develop simple and economical method for routine analysis of Maraviroc. The objective of present study was to develop and validate simple, accurate, precise, robust and economical method for estimation of Maraviroc in bulk and pharmaceutical formulations as per ICH Guidelines ${ }^{8}$.

Instruments and reagents: Reference standard of Maraviroc was kind gift from Hetro Laboratory, Hyderabad. All other ingredients used were of analytical grade. Double distilled water was used to prepare Solution. UV Visible Spectrophotometer (LABINDIA UV 3092 PC and UV3000+), spectral band width $1 \mathrm{~nm}$ and $1 \mathrm{~cm}$ matched quartz cells, Electric balance (Shimadzu).

Selection of Wavelength: Maraviroc is very soluble in Phosphate buffer $\mathrm{pH} 7.4$. The wavelength of maximum absorbance $\left(\lambda_{\max }\right)$ of Maraviroc in Phosphate buffer ( $\mathrm{pH} 7.4)$ was found $210 \mathrm{~nm}$ by scanning them over the UV range of $2000 \mathrm{~nm}$ to 400nm (Figure 2).

Preparation of working standard drug solution: Standard drug solution of Maraviroc was prepared by dissolving $100 \mathrm{mg}$ pure Maraviroc in phosphate buffer 7.4 and transferred into $100 \mathrm{ml}$ volumetric flask to obtain $1000 \mu \mathrm{g} / \mathrm{ml}$ of stock solution and the resulting Maraviroc Solution was used as working standard solution from which desired concentrations of solution were prepared.

Preparation of calibration curve: The standard solutions were prepared by the proper dilution of the primary stock solution with phosphate buffer $\mathrm{pH}$ 7.4 .From this primary solution, pipette out $1 \mathrm{ml}$ in $100 \mathrm{ml}$ volu metric flask and make up the volume with the buffer. From this, Transfer accurately $0.5,1,1.5,2,2.5,3.0,3.5,4.0$ and 4.5 to $10 \mathrm{ml}$ volumetric flasks and make up the volume with Phosphate buffer $\mathrm{pH} 7.4$. Such that the final concentration of $5,10,15,20,25,30,35,40,45 \mu \mathrm{g}$ $/ \mathrm{ml}$ and absorbances were taken at $\lambda \max 210 \mathrm{~nm}$ using an appropriate blank.
All the measurements were performed at room temperature. Averages of such 9 sets of values were taken for standard calibration curve, and the calibration curve was plotted.

Precision: Precision of the method was studied as intraday and Interday variations. Intraday precision was determined by analysing the $15 \mu \mathrm{g} / \mathrm{ml}$ of Maraviroc solution for 3 times in the same day. The interday precision of the method was also evaluated using two different analysts, day and different systems in the same laboratory. Precision was expressed as percentage relative standard deviation (Table 2).

Accuracy: To the preanalyzed sample solution, a known amount of standard stock solution was added at different levels, i.e. 50\%, 100\% and $150 \%$.The solution was reanalyzed by proposed method.

Ruggedness: Ruggedness of the proposed method is determined for $15 \mu \mathrm{g} / \mathrm{ml}$ concentration of Maraviroc by analysis of aliquots from a homogeneous slot by two different analysts using same operational and environmental conditions.

Repeatability: Repeatability was determined by analysing $15 \mu \mathrm{g} / \mathrm{ml}$ concentration of Maraviroc solution for six times.

LOQ and LOD: The limit of detection (LOD) and limit of quantification (LOQ) of proposed method were determined by using calibration curve. Maraviroc LOD and LOQ were calculated as $3.3 \sigma / \mathrm{S}$ and $10 \sigma / \mathrm{S}$, respectively, where $\sigma$ is the standard deviation of $\mathrm{Y}$ intercept (ICH guidelines) and $S$ is the slope of the Maraviroc calibration curve.

Analysis of Marketed Formulations: Twenty tablets of marketed brand of Maraviroc were weighed; average weight was determined and triturate to fine powder. An accurately weighed quantity of tablet powder equivalent to $150 \mathrm{mg}$ of Maraviroc was taken and extracted with $50 \mathrm{ml}$ of Phosphate buffer ( $\mathrm{pH}$ 7.4) solution under sonication for $30 \mathrm{~min}$.The Volume was made up to $100 \mathrm{ml}$ with Phosphate buffer and mixed; above solution was filtered through Whatman filter paper No. 41. A $1 \mathrm{ml}$ portion of the filtrate was further diluted with phosphate buffer $\mathrm{pH} 7.4$ in a $10 \mathrm{ml}$ 
volumetric flask up to mark $(10 \mu \mathrm{g} / \mathrm{ml})$ on label claim basis. The absorbance of the resulting solution was measured at $210 \mathrm{~nm}$ against solvent blank. The results of analysis are shown in (Table 7).

RESULT AND DISCUSSION: In the start of the method development for Maraviroc, different solvents were tested such as ethanol, water, Phosphate buffer ( $\mathrm{pH} 7.4$ ) and $0.1 \mathrm{~N} \mathrm{NaOH}$. Due to greater solubility and reproducible readings of maximum absorbance, Phosphate buffer ( $\mathrm{pH} 7.4)$ was selected for further work.The absorption spectrum of Maraviroc was measured in the range 200 to $400 \mathrm{~nm}$, against the blank solution Phosphate buffer ( $\mathrm{pH}$ 7.4) similarly prepared. From the drug scan it was found that the maximum Maraviroc UV absorbance occurs at 210nm (Figure 2) which was used as $\lambda_{\max }$ for the method development and the method was validated by studying the following parameters.

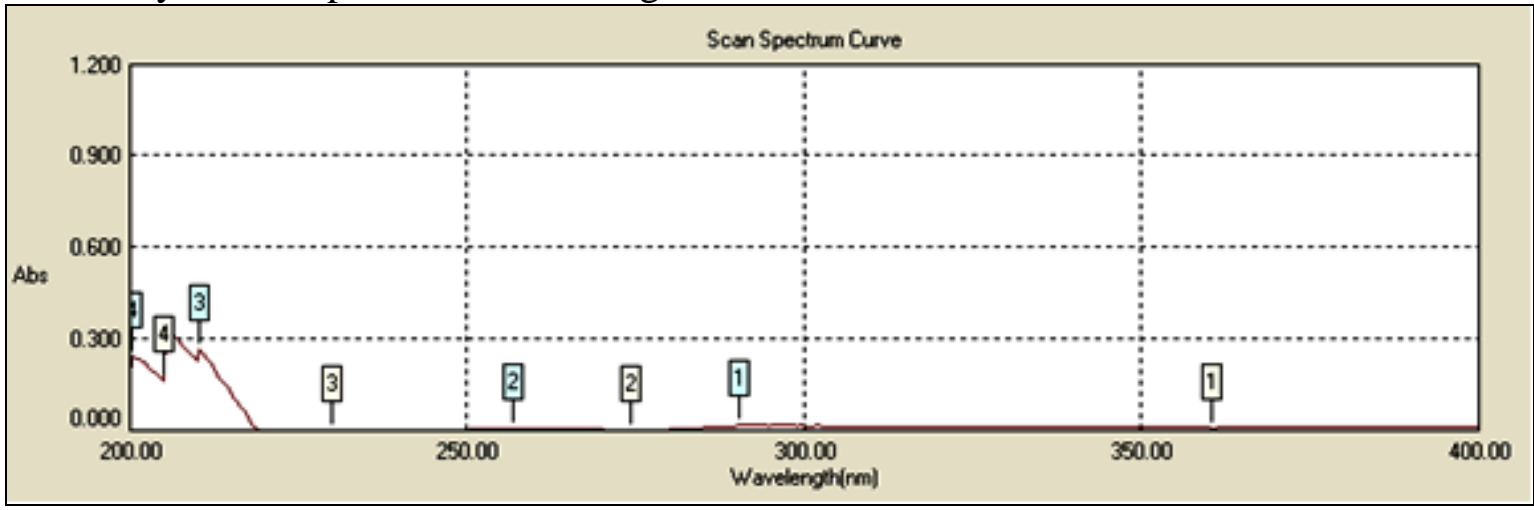

FIG. 2: UV SPECTRUM OF THE STANDARD MARAVIROC

Linearity: A linear relationship was found between the absorbance and the concentration of Maraviroc in the range of 5 to $45 \mu \mathrm{g} \mathrm{mL} \mathrm{L}^{-1}$. The calibration graphs were obtained by plotting the absorbance versus the concentration data and were treated by linear regression analysis.

The correlation coefficient was 0.999 indicating excellent linearity $(\mathrm{r} 2>0.999)$. The representative linear equation was $\mathrm{y}=0.020 \mathrm{x}+0.118$, calculated by the least squares method. The stock solutions and working standards were made in Phosphate buffer $(\mathrm{pH}$ 7.4). Linearity range and calibration curve is presented in Figure 3.

Precision: The precision of the method was expressed in terms of \% relative standard deviation (\%RSD).
The \% RSD values found to be less than 1 for intraday and interday precision, the precision data showed a good reproducibility. The result is expressed in Table 1.

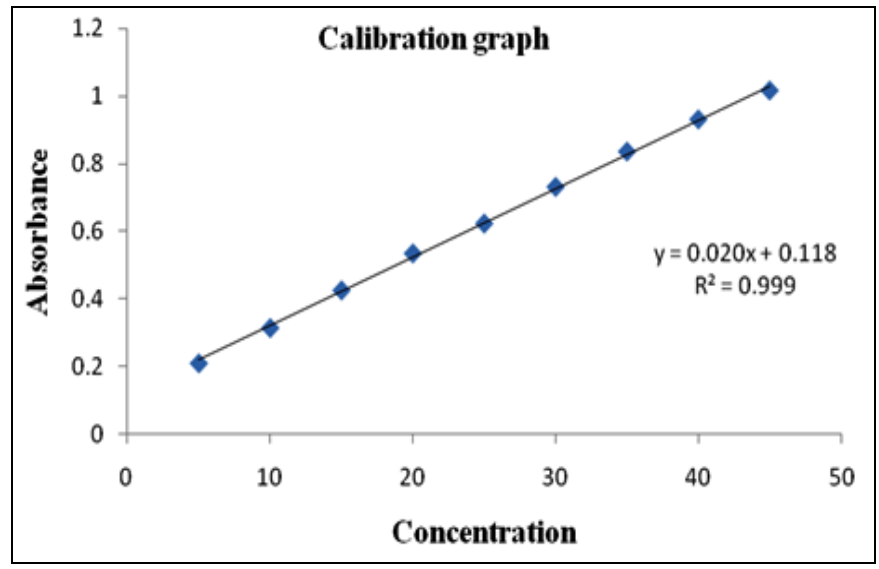

FIG. 3: CALIBRATION GRAPH

TABLE 1: INTERMEDIATE \& INTERDAY PRECISION

\begin{tabular}{cccccccc}
\hline \multirow{2}{*}{$\begin{array}{c}\text { Concentration } \\
(\boldsymbol{\mu g} / \mathbf{m l})\end{array}$} & \multicolumn{2}{c}{ \%RSD } & \multirow{2}{*}{ Average \%RSD } & \multicolumn{3}{c}{ \%RSD } & \multirow{2}{*}{ Average \% RSD } \\
\cline { 2 - 3 } \cline { 5 - 6 } & Instrument I & Instrument II & & Day1 & Day2 & Day3 & \\
\hline 15 & 0.425333 & 0.425167 & 0.3425 & 0.333 & 0.43 & 0.493 & 0.418667 \\
\hline
\end{tabular}

Repeatability: Repeatability was determined by analyzing $15 \mu \mathrm{g} / \mathrm{ml}$ concentration of Maraviroc solution for six times and \%RSD was found to be
0.00148 , which is less than 2 . The result is expressed in Table 2. 
TABLE 2: DATA FOR REPEATABILITY

\begin{tabular}{cccc}
\hline $\begin{array}{c}\text { Sample concentration } \\
(\boldsymbol{\mu g} / \mathbf{m l})\end{array}$ & No. of Measurement & Absorbance & Statistical Analysis \\
\hline & 1 & 0.426 & Mean- 0.426 \\
& 2 & 0.425 & SD- 0.000632 \\
$15 \mu \mathrm{g} / \mathrm{ml}$ & 3 & 0.427 & $\%$ RSD- 0.00148 \\
& 4 & 0.426 & \\
\hline & 5 & 0.426 & \\
\hline
\end{tabular}

Limit of Detection (LOD) and Limit of Quantification (LOQ): The LOD and LOQ of Maraviroc were determined by using standard deviation of the response and slope approach as defined in International Conference on Harmonization (ICH) guidelines. The LOD and LOQ were found $0.10428 \mu \mathrm{g} / \mathrm{ml}$ and $0.315 \mu \mathrm{g} / \mathrm{ml}$ respectively.
Accuracy (Recovery Test): As an additional check on the accuracy of the method was studied by recovery experiments. The recovery assay values for Maraviroc ranged from 100.7 to 103.9 with SD value not more than 1.5 which indicates good recovery at $50 \%$ to $150 \%$ estimation of Maraviroc (Table 3). No organic solvent is required for the extraction of Maraviroc from formulation which reduces the cost of estimation.

TABLE 3: DATA FOR ACCURACY TEST

\begin{tabular}{cccccc}
\hline $\begin{array}{c}\text { Concentration } \\
\text { level }\end{array}$ & $\begin{array}{c}\text { Sample } \\
\text { No. }\end{array}$ & $\begin{array}{c}\text { Amount added } \\
(\boldsymbol{\mu} \mathbf{g} / \mathbf{m l})\end{array}$ & $\begin{array}{c}\text { Amount Recovered } \\
(\boldsymbol{\mu g} / \mathbf{m l})\end{array}$ & \% Recovery & Statistical Analysis \\
\hline & 1 & 15 & 15.4 & 102.6 & Mean -103.2 \\
$50 \%$ & 2 & 15 & 15.59 & 103.9 & SD-.966 \\
& 3 & 15 & 15.44 & 102.9 & $\%$ RSD-0.645 \\
\cline { 2 - 6 } $100 \%$ & 1 & 30 & 30.89 & 102.9 & Mean - 101.55 \\
& 2 & 30 & 30.27 & 100.9 & SD-1.24 \\
& 3 & 30 & 30.22 & 100.7 & \%RD-1.22 \\
$150 \%$ & 1 & 45 & 45.58 & 101.2 & Mean -101.07 \\
& 2 & 45 & 45.5 & 101.1 & SD-0.28 \\
& 3 & 45 & 45.3 & 101.07 & \%RD-0.279 \\
\hline
\end{tabular}

Ruggedness: Ruggedness of this method was determined by analyzing the Maraviroc by two different analysts and the respective absorbance was noted and the results were indicated as percentage RSD (Table 4).

TABLE 4: RESULTS SHOWING RUGGEDNESS

\begin{tabular}{ccc}
\hline & Analyst 1 & \\
\hline Concentration $(\boldsymbol{\mu g} / \mathbf{m l})$ & Absorbance & Statistical analysis \\
\hline 15 & 0.424 & \\
15 & 0.424 & Mean -0.4245 \\
15 & 0.424 & SD-0.195 \\
15 & 0.425 & $\%$ RSD-0.197 \\
15 & 0.424 & \\
15 & 0.426 & \\
Analyst & & \\
15 & 0.425 & Mean -0.4126 \\
15 & 0.425 & SD- 0.499 \\
15 & 0.427 & $\%$ RSD- 0.50 \\
15 & 0.424 & \\
15 & 0.428 & \\
15 & 0.422 & \\
\hline
\end{tabular}


Robustness: Robustness of this method was determined by analyzing the Maraviroc in two different temperatures, room temperature and at $29^{\circ} \mathrm{C}$. From the below mentioned data (Table 5), it was observed that the method is robust enough to analyze Maraviroc Tablet.

TABLE 5: RESULTS SHOWING ROBUSTNESS

\begin{tabular}{ccc}
\hline & Room temperature & \\
\hline Concentration $(\boldsymbol{\mu g} / \mathbf{m l})$ & Absorbance & Statistical analysis \\
\hline 15 & 0.425 & Mean -0.425 \\
15 & 0.424 & SD- 0.001 \\
15 & 0.425 & $\%$ RSD-0.241 \\
Temperature $29^{\circ} \mathrm{C}$ & & \\
15 & 0.424 & Mean -0.424 \\
15 & 0.424 & SD- 0.518 \\
15 & 0.425 & $\%$ RSD- 0.110 \\
\hline
\end{tabular}

Determination of Maraviroc in Tablets: The validated method was applied to the determination of Maraviroc in Tablets. Six tablets were assayed and the results are shown in Table 6 indicating that the amount of drug in tablet samples meet with requirements (99-102\% of the label claim).

TABLE 6: RESULTS OF ANALYSIS OF FORMULATIONS

\begin{tabular}{cccccc}
\hline Drug & Labeled amount $(\mathbf{m g} /$ tab) & Amount present & \% Amount Present & SD & \% RSD \\
\hline Maraviroc & 150 & 0.426333 & 99.73 & 0.505 & 0.506 \\
\hline
\end{tabular}

CONCLUSIONS: A spectrophotometric method for quantifying Maraviroc in formulation samples has been developed and validated. The proposed method is simple, accurate, precise, economical, robust and can be used for routine analysis of Maraviroc in bulk and Pharmaceutical formulation.

ACKNOWLEDGMENT: The authors are thankful to Hetro Lab, Hyderabad for providing gift samples. Authors are also thankful to The Principal K.L.R Pharmacy College, Paloncha, Andhra Pradesh, for permitting to carry out research work.

\section{REFERENCES:}

1. Vandekerckhove L, Verhofstede C, Vogelaers D. MARAV IROC: Integration of a new antiretroviral drug class into clinical practice. Journal of Antimicrobial Chemotherapy 2008; 61: 1187-1190.

2. MacArthur RD, Novak RM. Reviews of anti-infective agents: Maraviroc: the first of a new class of antiretroviral agents. Clinical Infectious Diseases 2008; 47: 236-241.
3. Abel S, Back DJ, Vourvahis M. Maraviroc: Pharmacokinetics and drug interactions. Antiviral therapy 2009; 14(5):607-18.

4. Beniam Ghebremedhin. Maraviroc in Antiretroviral-Naive HIV-1 Patients. Infectious Diseases: Research and Treatment 2012; 5:1-13

5. Samantha abel,David J back and Manoli vourvahis. Maraviroc: pharmacokinetics and drug interactions. Antiviral therapy 2009; 14:607-618.

6. V.Kalyana chakravarthy and D.Gowri sankar. Stability indicating HPLC method for Determination of maraviroc and its Degradants/impurities in bulk and Pharmaceutical formulation. Rasayan Journal of chemistry 2012; 5(1): 90105.

7. V. Kalyana Chakravarthy and D. Gowri Sankar. Development and validation of RP-HPLC method for Maraviroc in bulk and its pharmaceutical formulation. International Journal of Pharmaceutical Research and Development 2011; 3(10): 72-79.

8. Jaydeep Patel, Garala Kevin, Anjali Patel, Mihir Raval, and Navin Sheth. Development of the UV spectrophotometric method of Olmesartan medoxomil in bulk drug and pharmaceutical formulation and stress degradation studies. Pharmaceutical Methods 2011; 2(1): $36-41$.

How to cite this article:

Velmurugan S and Ali MA: Analytical method development and validation of Maraviroc in bulk and pharmaceutical formulation by UV spectroscopy. Int J Pharm Sci Res 2013; 4(11): 4366-70. doi: 10.13040/IJPSR. 0975-8232.4(11).4366-70

All $\odot 2013$ are reserved by International Journal of Pharmaceutical Sciences and Research. This Journal licensed under a Creative Commons Attribution-NonCommercial-ShareAlike 3.0 Unported License.

This article can be downloaded to ANDROID OS based mobile. Scan QR Code using Code/Bar Scanner from your mobile. (Scanners are available on Google Playstore) 